\title{
EFFICACY OF HYBRID ADSORPTION/MEMBRANE PRETREATMENT FOR LOW PRESSURE MEMBRANE
}

\author{
Malczewska B. ${ }^{1,2}$, Benjamin M.M. ${ }^{1}$
}

1. Civil and Environmental Engineering, University of Washington

Box 352700, Seattle, WA 98195-2700

email: markbenj@uw.edu Phone: 206-543-7645

2. Wroclaw University of Environmental and Life Sciences, The Faculty of

Environmental Engineering and Geodesy, pl. Grunwaldzki 24; 50-363 Wroclaw

\section{ABSTRACT}

Fouling by natural organic matter (NOM) is a major obstacle when water from natural sources is treated using low-pressure membranes. Prior research by our group has demonstrated that passing natural water through a thin, pre-deposited layer of heated aluminum oxide particles (HAOPs) can remove substantial amounts of NOM from the feed and thereby reduce the fouling rate of downstream membranes. The work reported here explored the technical efficacy of such a pretreatment process under more challenging (and therefore realistic) conditions than reported earlier. Several analytical techniques were applied to the feed and permeate in an attempt to identify the key fouling components. The results demonstrate that a HAOPs layer can be pre-deposited on a stainless steel mesh and then be readily washed off at the end of a filtration cycle with very little irreversible fouling due to residual NOM or HAOPs 
23 left on the mesh. In addition, the pretreatment step removes enough foulant to allow

24 a downstream UF membrane to operate at significantly higher fluxes than when

25 conventional pretreatment is applied. HAOPs pretreatment also reduced the 26 formation of chlorinated and brominated trihalomethanes (THM4) by more than $67 \%$ 27 and of haloacetic acids (HAA9) by $64 \%$ to $88 \%$ in simulated distribution system 28 (SDS) tests.

Keywords: Membrane fouling; Natural organic matter; Aluminum oxide particles, 31 HAOPs, precoat filtration

\section{INTRODUCTION}

34 Ultrafiltration (UF) membranes are widely used in drinking water treatment because they are capable of removing most colloidal and particulate matter from the feed while operating at relatively low transmembrane pressure (TMP). However, their flux and long-term performance are limited by membrane fouling, a complex physicochemical phenomenon caused by dissolved organic matter, inorganic and organic colloids, and biological growth and its byproducts (Hilal et al. 2005). Natural organic matter (NOM), comprising both allochthonous inputs such as terrestrial and 41 vegetative debris and autochthonous inputs from algae (Cipollina et al. 2009), is 42 often implicated as an important contributor to both the reversible and irreversible 43 fouling (Huang at al. 2009, Hilal et al. 2005, Judd and Hills 2001). In addition to 44 contributing to fouling, NOM has the potential to transport metals and hydrophobic 45 organic chemicals, contribute to color, taste, and odor of the water, and react with 46 disinfectants to form disinfection byproducts (DBPs). 
47 Numerous studies have been carried out to identify the properties of NOM that 48 cause, or at least are correlated with, membrane fouling. These studies have often 49 focused on the molecules' hydrophobicity or molecular weight (Howe and Clark 2002, 50 2006, Yuan and Zydney 1999, 2000, Cho et al. 2000, Lin et al. 2000, Hua et al. 51 2015). While many researchers have suggested that humic substances are 52 responsible for most of the fouling of low-pressure membranes (Yuan and Zydney 53 1999, 2000, Combe et al. 1999), others have argued that the hydrophilic fraction of 54 the NOM, especially polysaccharides and proteins, might be more significant 55 (Jermann et al. 2007, Lin et al. 2000, Carroll et al. 2000). According to some studies, 56 hydrophilic NOM leads to rapid flux decline and the formation of a cake or gel layer, 57 while hydrophobic NOM induces a steady flux decline without obvious formation of 58 such a layer (Gray et al. 2007). TEP (Transparent Exopolymer Particles) are suspected to be major contributors to biofouling, since they can adhere to the membrane surface and provide a nutritious substrate for microbial growth and 61 establishment of biofilm (Bermana et al. 2011, Tsuneda et al. 2003, Nguyen et al. 62 2009).

63 Proper pretreatment to minimize fouling is essential for successful UF operation. The 64 most common and economical pretreatment process is coagulation, which invariably 65 removes a portion of the NOM (typically, 20-60\%) and usually mitigates fouling, but 66 not always (Lee at al. 2000, Choi et al. 2004, Judd and Hills 2001, Kabsch67 Korbutowicz et al. 2006, Pikkerainen et al. 2004). For example, Li et al. (2010) 68 reported that reversible fouling was reduced by coagulation pretreatment, but 69 irreversible fouling was unchanged, and Zhang et al. (2014) found that the most 70 severe membrane fouling was caused by dissolved organic matter (DOM), which was 71 the most difficult foulant to remove by backwashing. Fan et al. (2008) reported that 
pretreatment with coagulation does not prevent the formation of a gel layer, but does reduce fouling.

Heated aluminum oxide particles (HAOPs) are a new adsorbent that is effective at removing NOM, including much of the NOM responsible for membrane fouling (Kim et al. 2007, 2008, 2010). Early research on HAOPs focused on the amounts and properties of NOM molecules that HAOPs bind, using test systems that could not easily be backwashed. HAOPs were shown to preferentially remove foulant over nonfoulant NOM molecules, especially when the HAOPs were applied to the membrane as a pre-deposited (pre-coat) layer (Cai at al. 2008, Cai 2012, Kim et al. 2007, 2008,

81 2010). More recent work demonstrated that, in systems receiving equal doses of $\mathrm{Al}$ (i.e. mg Al per liter of water treated), passing the raw water through a layer of predeposited HAOPs was more effective at removing NOM and mitigating fouling than 84 adding either alum or HAOPs to the bulk feed, even though the former system was 85 backwashed only one-tenth as frequently as the latter two (Malczewska et al. 2015). 86 This study explored the performance of HAOPs in backwashable systems under more challenging conditions and characterized the interactions of HAOPs with NOM using several analytical techniques.

MATERIALS AND METHODS

Raw water

Water was collected near the shoreline of Lake Union (LU) adjacent to the University of Washington in Seattle, WA. Water flows into LU from Lake Washington through

93 the Montlake Cut and out via the Fremont Cut on its way to Puget Sound. The lake 94 has a surface area of $\sim 2.3 \mathrm{~km}^{2}$ and a mean depth of $\sim 10 \mathrm{~m}$, and most of the NOM in 95 the lake is thought to be allochthonous. Typical values of water quality parameters 
during the study were: $\mathrm{pH}$ 6.8, UV $\mathrm{UV}_{254} 0.0495 \mathrm{~m}^{-1}$, DOC $2.0 \mathrm{mg} / \mathrm{L}$, SUVA 254

$972.5 \mathrm{~cm}^{-1}(\mathrm{mg} / \mathrm{L})$, and turbidity $0.68 \mathrm{NTU}$.

HAOPs and HAOPs Support Tubes

99 HAOPs were prepared according to the method of Cai et al. (2008). Briefly, a solution 100 of alum (10 g/L as Al) was neutralized to $\mathrm{pH} 7.0$ with $\mathrm{NaOH}$, and the suspension 101 containing $\mathrm{Al}(\mathrm{OH})_{3}$ precipitate was heated in a closed container at $110^{\circ} \mathrm{C}$ for $24 \mathrm{~h}$. 102 Particles generated in this way have diameters in the range $1.5-30 \mu \mathrm{m}$. The 103 suspension was cooled and stored at room temperature until use. Just before use, 104 the portion of the suspension to be used in the upcoming experiment was dosed with 105 bleach to achieve a free chlorine concentration of $50 \mathrm{mg} / \mathrm{L}$ as $\mathrm{Cl}_{2}$.

106 In the experiments, HAOPs were deposited on the interior surface of stainless steel 107 mesh tubes fabricated by Cascade Designs, Inc. (Seattle, WA). The mesh was a

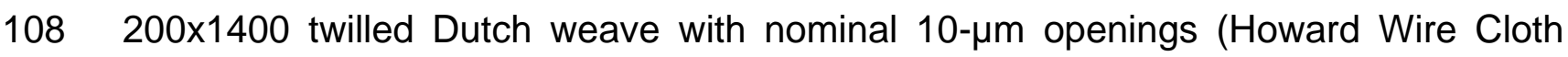
109 Co., Hayward, CA). The tubes were $60 \mathrm{~cm}$ long, with an internal diameter of $2.54 \mathrm{~cm}$ 110 (Figure 1).

111 Ultrafiltration membrane

112 A UF membrane mini-module (Seccua GmbH, Steingaden Germany) containing 159 113 polyethersulfone (PES) hollow fibers with a nominal pore size of $8 \mathrm{~nm}$ and total 114 membrane surface area of $0.079 \mathrm{~m}^{2}$ was used. The contact angle for water on this 115 membrane was not measured, but reported contact angles for water on other PES 116 membranes are typically near $45^{\circ}$. 
117 Operating conditions

118 A schematic diagram of the experimental setup is shown in Figure 2. To initiate a run, 119 a stock solution of HAOPs was circulated axially through the mesh tube while 120 maintaining a water flux of 225 liters per square meter per hour $(\mathrm{LMH})$ across the 121 wall. The flux carried the HAOPs to the wall, where they were captured and 122 deposited in a thin layer $(120 \mu \mathrm{m})$. The typical duration of this deposition step was 2.5 $123 \min$.

124 LU water was then delivered to the mesh tubes by peristaltic pumps at a constant flux 125 in dead-end filtration mode. After passing through the HAOPs and the mesh, the 126 water was collected in a reservoir and fed to the UF module. The mean hydraulic 127 residence time in the reservoir varied from 8 to 24 hours, depending on the fluxes 128 through the two units in the given experiment. The pressure drops across the HAOPs/mesh pretreatment unit and the UF module were measured online using 130 transducers (Omega, PX302-100GV). In this paper, both pressure drops are referred 131 to as transmembrane pressures (TMPs), even though the pretreatment unit is not 132 truly a membrane.

133 The HAOPs filtration process and the cleaning of the HAOPs unit were automated, 134 with a cleaning step triggered when the run-time reached 24 hours or when the TMP 135 reached $55 \mathrm{kPa}$ (8 psi), whichever came first. However, in the experiments reported 136 here, the TMP never reached the trigger point, so all cycles lasted 24 hours. Treated 137 water samples were collected at pre-selected intervals for analysis. The cleaning step 138 lasted approximately 2.5 min and included backwashing in conjunction with four to six 139 10- to 15-s pulses during which water and air were injected into the interior of the 
140 tube, and a final flush with water only. Fresh HAOPs were deposited on the mesh

141 before the next treatment cycle.

142 The UF module was cleaned intermittently by simultaneous backwashing and

143 flushing with water. In some cases, the backwash water was amended with bleach to

144 make a $1 \% \mathrm{NaOCl}$ solution; in these instances, the membrane was rinsed with

145 deionized water before being put back into service. The goal of this chemical 146 cleaning was to reduce or eliminate fouling; the $\mathrm{NaOCl}$ concentration was not 147 optimized and, in all likelihood, could have been reduced substantially.

\section{ANALYTICAL METHODS}

$149 \mathrm{UV}_{254}, \mathrm{DOC}$

150 Ultraviolet absorbance at $254 \mathrm{~nm}\left(\mathrm{UV}_{254}\right)$ and total organic carbon (TOC) 151 concentrations were used to quantify the concentration of organics in the water. $152 \mathrm{UV}_{254}$ was measured using a dual-beam spectrophotometer (Perkin-Elmer Lambda153 18) with a $1-\mathrm{cm}$ quartz cell. Spectral data were acquired at wavelengths of $200-400$ $154 \mathrm{~nm}$ at $1-\mathrm{nm}$ resolution. DOC was determined on filtered samples with a TOC analyzer 155 (Shimadzu TOC-VCSH). Reliable DOC values could not be obtained in a few 156 experiments due to instrumental malfunction. However, strong correlations were 157 obtained between $U_{254}$ and the $\mathrm{DOC}$ concentration, so $\mathrm{UV}_{254}$ was used as the 158 primary indicator of NOM concentration in those cases.

159 Size Exclusion Chromatography (SEC)

160 SEC analyses used a DIONEX Ultimate 3000 HPLC system coupled to a SIEVERS 161 turbo total organic carbon analyzer. Isocratic flow of $0.01 \mathrm{M} \mathrm{NH}_{4} \mathrm{HCO}_{3}$ was delivered 162 through a column $(300 \times 7.5,8 \mathrm{um})$ at $0.5 \mathrm{~mL} / \mathrm{min}$. 
164 Three-dimensional EEM spectrometry was carried out at ambient temperature to help 165 characterize the organic material in the feed and treated waters. A 166 spectrofluorometer (HORIBA Scientific Fluorescence Spectroscopy, Edison, NJ) 167 equipped with a 150-W xenon lamp was used in conjunction with a 1 -cm quartz 168 cuvette with four optical windows. Emission scans were performed from 200 to 500 $169 \mathrm{~nm}$ after excitation at wavelengths from 300 to $450 \mathrm{~nm}$, both at $4-\mathrm{nm}$ intervals. The 170 scanning speed was $1200 \mathrm{~nm} / \mathrm{min}$, and the slit widths for excitation and emission 171 were both $4 \mathrm{~nm}$. The fluorescence spectrum of Milli-Q water, obtained under the 172 same conditions, was subtracted from all the spectra to eliminate water Raman 173 scattering and to reduce other background noise.

174 Fourier Transform Infrared Spectroscopy (FT-IR)

175 FT-IR spectra of the raw water and HAOPs-treated water were recorded on a Bruker 176 Biospin Corporation Spectrophotometer at wavenumbers from 4000 to $400 \mathrm{~cm}^{-1}$ with 177 a resolution of $4 \mathrm{~cm}^{-1}$. The samples were dried in an oven $105^{\circ} \mathrm{C}$, and then pellets 178 were prepared by pressing, under vacuum, a mixture of $\sim 1 \mathrm{mg}$ of sample and $200 \mathrm{mg}$ 179 of $\mathrm{KBr}$ (spectroscopy grade).

180 Transparent Exopolymer Particles (TEP)

181 A version of the spectrophotometric technique developed by Silvia et al. (2004) was 182 applied for the determination of TEP. In this method, TEP reacts with excess alcian 183 blue to yield a low solubility dye-TEP complex. After centrifugation, the concentration 184 of the remaining dye in the supernatant was determined based on the sample's 185 absorbance at $602 \mathrm{~nm}\left(\mathrm{~A}_{602}\right)$, and the concentration of TEP in the original sample 186 was inferred based on comparison of that value with $A_{602}$ when the same procedure 
187 was applied to a blank (DI water). A standard curve was prepared by applying the 188 procedure to solutions of $\mathrm{DI}$ water amended with known concentrations of xantan 189 gum.

Disinfection byproducts (DBPs)

191 DBP formation was evaluated in simulated distribution system (SDS) tests on the raw 192 water and composites of treated water from 24-h filtration runs. The chlorine doses 193 were selected to yield residual concentrations of free chlorine of $\sim 1.0 \mathrm{mg} / \mathrm{L}$ as $\mathrm{Cl}_{2}$. 194 Trihalomethane (THM) and haloacetic acid (HAA) concentrations were determined 195 using USEPA Methods 501.1 and 552.2, respectively.

\section{RESULTS AND DISCUSSION}

197 In drinking water treatment applications, UF membranes are typically operated in a 198 flux range of 50 to $100 \mathrm{LMH}$, with lower fluxes used for feed waters with high 199 suspended solids and/or fouling potential. For the initial experiment, the treatment 200 system was operated with a HAOPs loading of $7.5 \mathrm{~g} \mathrm{Al} / \mathrm{m}^{2}$ on the upstream mesh, 201 and fluxes of $150 \mathrm{LMH}$ and $87 \mathrm{LMH}$ applied to the mesh and UF stages, respectively. 202 The UF module was operated continuously without any backwashing or other 203 cleaning steps for the whole duration of this experiment (11 d).

204 Figure 3a shows the TMP across each stage of treatment throughout this experiment. 205 The average TMP increase across the HAOPs unit during a single (one-day) cycle 206 was $5.3 \mathrm{kPa}(0.78 \mathrm{psi})$, and that TMP increase was almost fully reversed by hydraulic

207 cleaning. The TMP increase across the downstream UF module was only $7.0 \mathrm{kPa}$ 208 (1.0 psi) during the entire 11-d experiment, despite the fact that that unit was not 209 cleaned at all. 
210 Because UF removes a negligible portion of the $U_{254}$ from feed waters, essentially

211 all the $U_{254}$ removal in this system occurred in the upstream HAOPs unit. The UV 254 212 profiles fluctuated during the first four days of the test, but then stabilized and were 213 very similar day-to-day thereafter (Figure 3b); the overall average removal over the 214 full experiment was $\sim 70 \%$. The TOC removal efficiency (not shown) followed a 215 similar pattern, typically declining from $55-60 \%$ at the beginning of a cycle to $45-50 \%$ 216 at the end during days 5-11 of the test. Consistent with previous findings (Cai 2008, 217 Kim at al. 2007, 2008, 2010), UV 254 removal by the HAOPs was more efficient than 218 DOC removal, suggesting that the HAOPs selectively bind more hydrophobic 219 molecules (Cai 2012).

220 Next, the system was challenged by increasing the fluxes to both components: from 221150 to $210 \mathrm{LMH}$ for the HAOPs unit, and from 87 to either 261 or $400 \mathrm{LMH}$ for the UF 222 unit. The HAOPs unit performed well throughout this test, with TMP increasing from $223 \sim 20 \mathrm{kPa}$ at the beginning of each cycle to between 25 and $35 \mathrm{kPa}$ at the end (Figure $2244)$.

225 When the flux to the UF unit was $261 \mathrm{LMH}$, the TMP across the unit during the first 226 cycle increased much more rapidly than it had during the prior test at $87 \mathrm{LMH}$ (Figure 227 4). The module was therefore subjected to chemically-enhanced hydraulic cleaning 228 (using water containing $1 \% \mathrm{NaOCl}$ ), which dramatically lowered the TMP buildup. 229 The unit was then operated on a 24-hr filtration cycle with chemically-enhanced 230 cleaning for five more cycles, during which the TMP buildup averaged less than $23110 \mathrm{kPa}$ per day.

232 Finally, the flux to the UF unit was increased to $400 \mathrm{LMH}$ for three, 24-hour cycles, 233 again applying chemically-enhanced cleaning between cycles. As would be 
234 expected, both the TMP at the beginning of each cycle and the TMP increase during 235 each cycle were higher than in the prior tests. Nevertheless, the TMP increase was 236 less than $28 \mathrm{kPa}$ (4 psi) per day (Figure 4), which might be considered an acceptable 237 burden in exchange for operating at such a high flux (and thereby reducing the 238 required size of the membrane plant).

239 The $U_{254}$ removal efficiency during the first five cycles (i.e., five days) of this test 240 was essentially identical to that in the prior test at lower flux, averaging close to $70 \%$. 241 In the sixth cycle, the composite $U V_{254}$ removal efficiency declined to $~ 50 \%$, where it 242 remained for the next four cycles (Figure 4). This change in performance coincided 243 with a visible darkening of the feed water, although no significant change was 244 detected in the TOC or $U_{254}$. It was subsequently determined that the salinity of the 245 feed (which was drawn from near the bottom of the lake) had increased and was 246 approximately triple that of the surface water; unfortunately, the time when that 247 discrepancy first occurred could not be determined ex poste facto. A plausible 248 hypothesis for these observations is that saline water had entered the lake from the 249 downstream locks separating the lake from Puget Sound and had migrated to near 250 the sampling point. Prior experiments had indicated that increases in salinity on the 251 order of those detected would not have a severe effect on $U_{254}$ removal, but the 252 changes in salinity and color nevertheless suggest that the water quality underwent a 253 significant change, and other features of that change might have caused the 254 observed behavior.

255 Because the TMP buildup in the HAOPs/mesh unit during a single cycle was modest 256 throughout this test, it is difficult to determine whether that parameter was affected by 257 the change in water quality. However, it is worth noting that the TMP across that unit 258 did decline steadily during the period of changed feed quality, concomitant with the 
259 deterioration in $U_{254}$ removal. Thus, it is plausible that the decreased removal of

260 NOM by the HAOPs led to decreased "fouling" of the HAOPs layer, and that 261 correspondingly more foulant entered the UF unit during the latter stages of testing.

262 CHARACTERIZATION OF RAW AND HAOPS-TREATED WATER

$263 \mathrm{NOM}$ is a heterogeneous mixture of organic compounds that serve as the precursors 264 of chlorinated disinfection by-products (DBPs) and contribute to fouling. In an effort 265 to identify those components that are especially important for fouling, the apparent 266 molecular weight (AMW) distribution and the EEM fluorescence and FT-IR spectra of 267 the NOM were acquired, and the TEP concentration of the feed and HAOPs-treated 268 water were analyzed. The latter samples were collected immediately downstream of 269 the HAOPs/mesh unit (i.e., before the UF unit) when the unit was operating at a flux 270 of $210 \mathrm{LMH}$ and the $\mathrm{UV}_{254}$ removal efficiency was $\sim 70 \%$.

271 The SEC chromatogram of the raw water (Figure 5) had four substantial and partially 272 overlapping peaks at retention times of 10-25 min, and several additional small peaks 273 at longer and shorter times. The four major peaks are labeled in order of decreasing 274 AMW in Figure 5. HAOPs removed some portion of all the fractions, with removal 275 efficiencies of $85 \%, 78 \%, 54 \%$, and $69 \%$ for peaks 1 through 4 , respectively (based 276 on peak heights).

277 Fluorescence of organics in natural waters is commonly analyzed with respect to five 278 regions or peaks of the excitation/emission (EX/EM) spectrum (Chen et al. 2003, Fan 279 et al. 2008). Region I is associated with protein-like extracellular organic matter 280 containing aromatic amino acids such as tryptophan and tyrosine; Region II is 281 attributed to aromatic proteins and BOD-type substances; Region III is associated 282 with soluble microbial products (SMPs, mainly polysaccharides and proteins); Region 
283 IV contains fulvic-like fluorophores; and Region $V$ comprises humic acid-like 284 substances. The fluorescence intensity of the peaks depends primarily on the 285 identities and concentrations of the contributing components (You et al. 2015), but 286 other factors (e.g., salinity) can also play a role (Gusso-Choueri et al. 2011). For 287 example, amino acids or protein-like components in river waters are often bound with 288 humic and fulvic substances, and this binding can cause significant variability in the 289 emission wavelength (Mostofa 2005).

290 The EEM spectra of raw water and HAOPs-treated water had intense peaks at 291 EX/EM wavelengths (nm) of 245/342 (Peak A), and 305/335 (Peak B) (Figure 6), 292 most likely attributable to protein-like and fulvic-like matter, respectively. The peak for 293 fulvic-like material is blue shifted relative to the normal location for such material, 294 which might reflect heterogeneity of the fluorophores contributing to that peak or, 295 possibly, the salinity of the sample. The presence of only fulvic-like and aromatic296 protein-like fluorescence is unusual for a natural water and suggests that the NOM in 297 the test water was richer in hydrophilic material than in humic-like material. The 298 maximum fluorescence intensity of both peaks in the EEM spectra decreased by $48 \%$ 299 when the water passed through the HAOPs layer, indicating that significant amounts 300 of both aromatic protein-like substances and fulvic-like substances were removed by 301 the HAOPs.

302 Figure 7 shows FT-IR spectra of these samples, normalized by assigning the highest 303 peak an intensity of 1.0 . In both cases, this peak was in the $3300 \sim 3400 \mathrm{~cm}^{-1}$ range, 304 which is typically associated with the $\mathrm{O}-\mathrm{H}$ vibrations in water and carbohydrate-like 305 organic matter. Peaks in this region might also indicate the presence of aluminum 306 silicates. However, aluminum silicates also have an intensive band between 1030 307 and $1020 \mathrm{~cm}^{-1}$, which is not present in these samples. 
308 The molecules responsible for the absorption in the $3300 \sim 3400 \mathrm{~cm}^{-1}$ range are 309 expected to be minimally affected by contact with HAOPs. In the limiting case where 310 these molecules are not removed at all by passage through the HAOPs layer, the 311 normalization procedure would fully account for any difference in the NOM masses 312 between in the two samples (raw water and HAOPs-treated water). In that case, the 313 ratios of the other peak heights in the two samples (that is, the ratio of a given peak 314 height in the HAOPs-treated sample to that in the raw water) would be a direct 315 indicator of the efficiency with which HAOPs removed the functional groups 316 responsible for those peaks.

317 Significant signals in the FT-IR spectra other than the one used for the normalization 318 include those associated with $\mathrm{C}=\mathrm{C}$ stretching in aromatic compounds $\left(1618 \mathrm{~cm}^{-1}\right)$, $319 \mathrm{~N}-\mathrm{C}=\mathrm{O}$ in amides (the amide I peak at $1636 \mathrm{~cm}^{-1}$ ), $\mathrm{COOH}$ groups in humic and fulvic 320 substances $\left(2200 \sim 2900 \mathrm{~cm}^{-1}\right)$, and methyl group $\mathrm{CH}$ bending $\left(1385 \mathrm{~cm}^{-1}\right)$. The 321 relative peak heights in the two normalized spectra suggest that at least $78 \%$ to $95 \%$ 322 of the humic and fulvic acids in the raw water were removed by HAOPs treatment, 323 whereas aromatic proteins were removed much less efficiently (10\% to $25 \%$, based 324 on the change in height of the amide I peak). According to Howe et al. (2002), 325 polysaccharide-like materials, which are thought to be strong foulants of membranes, 326 have an IR absorption band near $1000-1100 \mathrm{~cm}^{-1}$. The samples did have a broad 327 band in that region, and its height declined by about $70 \%$ when the water was treated 328 by HAOPs.

329 The average TEP concentration in the raw water was $65 \mu \mathrm{g} / \mathrm{L}$ (as xanthan gum 330 equivalents). TEP removal by HAOPs was $64 \%$, closely mimicking the estimated 331 removal of polysaccharide-like material based on the FT-IR spectra. 
332 The effectiveness of pre-deposited HAOPs at removing DBP precursors was

333 evaluated in SDS tests conducted in winter and spring; an additional test was 334 conducted to check the impact of filtration time on DBP removal. The results of all 335 these tests are shown in Table 1.

336 In all the tests, chloroform and DCBM were the dominant DBPs formed. The 337 reduction in THM formation was greatest for chloroform and declined steadily as the $338 \mathrm{Br}$ content of the THM increased; the same trend applied to HAAs. HAOPs 339 pretreatment reduced the THM4 concentration by more than $67 \%$ and the HAA9 340 concentration by $64 \%$ to $88 \%$.

\section{SUMMARY AND CONCLUSIONS}

342 This project investigated a hybrid adsorbent/membrane process comprising a 343 pretreatment step in which water is passed through a pre-deposited layer of HAOPs, 344 followed by a conventional membrane filtration step. The process was effective for 345 removal of NOM in general, including DBP precursors, and was selectively and 346 remarkably effective for removal of membrane foulants. UF membranes receiving 347 HAOPs-treated lake water as feed were operated at conventional fluxes for almost 348 two weeks without backwashing and with no significant fouling, and others were 349 operated successfully at fluxes as high as $400 \mathrm{LMH}$ for filtration cycles of 24 hours.

350 HAOPs selectively removed high-AMW fractions from the raw lake water and also 351 removed most fluorophores. EEM analysis indicated that humic and fulvic 352 substances, as well as aromatic proteins, are effectively removed by HAOPS 353 treatment. FT-IR data strongly supported the inferences about humics and fulvics, but 354 were less supportive of the inferred removal of the proteins. FT-IR and TEP data 355 suggested that HAOPs also remove (non-fluorescent) polysaccharide-like materials, 
356 which might account for the substantial benefits of HAOPs with respect to fouling 357 mitigation.

358

\section{ACKNOWLEDGEMENTS}

360 This work has been supported by Grant N00014-12-1-0129 from the Office of Naval

361 Research. We also gratefully acknowledge Fellowship support for Beata Malczewska 362 from the Kosciuszko Foundation. Assistance and critiques provided by Martyna 363 Horochowska, James Liu, Siamak Modaressi, and Long-fei Wang are gratefully 364 acknowledged. The UF mini-module was generously provided by Seccua GmbH 365 (Steingaden, Germany).

366

\section{REFERENCES}

368 Bermana T., Mizrahia R., Dosoretzb C.G., 2011. Transparent exopolymer particles 369 (TEP): A critical factor in aquatic biofilm initiation and fouling on filtration membranes. 370 Desalination $276(1-3)$, 184-190.

371 Cai Z., Kim J., Benjamin M.M., 2008. NOM removal by adsorption and membrane 372 filtration using heated aluminum oxide particles. Environmental Science and 373 Technology 42, 619-623.

374 Cai Z., 2012. Investigation of Microgranular Adsorptive Filtration Systems, Ph.D. 375 Dissertation, University of Washington 
376 Carroll, T., King S., Gray S. R., Bolto B. A., Booker N. A., 2000. The fouling of 377 microfiltration membranes by NOM after coagulation treatment. Water Research 34 378 (11), 2861-2868.

379 Chen W., Westerhoff P., Leenheer J.A., Booksh K., 2003. Fluorescence 380 Excitation-Emission Matrix Regional Integration to Quantify Spectra for Dissolved 381 Organic Matter. Environmental Science and Technology 37 (24), 5701-5710; doi: $38210.1021 / \mathrm{es} 034354 \mathrm{c}$

383 Cipollina A., Micale G., Rizzuti L., 2009. Seawater Desalination: Conventional and 384 Renewable Energy Processes, Springer Science \& Business Media

385 Cho J. W., Amy G. , Pellegrino J., 2000. Membrane filtration of natural organic 386 matter, comparison of flux decline, NOM rejection, and foulants during filtration with 387 three UF membrane, Desalination, 127 (2000), 283-289.

388 Choi K. Y., Dempsey B. A., 2004. In-line-coagulation with low-pressure membrane 389 filtration. Water Research 38 (19), 4271-4281.

390 Combe C., Molis E., Lucas P., Riley R., Clark M. M., 1999. The effect of CA 391 membrane properties on adsorptive fouling by humic acid. Journal of Membrane 392 Science 154 (1), 73-87; doi:10.1016/S0376-7388(98)00268-3

393 Fan L., Nguyen T., Roddick F. A., Harris J. L. 2008. Low-pressure membrane 394 filtration of secondary effluent in water reuse: Pretreatment for fouling reduction, 395 Journal of Membrane Science 320 (2008), 135-14; 396 doi:10.1016/j.memsci.2008.03.058

397 Gray S.R., Ritchie C.B., Tran T., Bolto B.A. 2007. Effect of NOM characteristics and 398 membrane type on microfiltration performance. Water Research 41 (17), 3833-41; 
400 Gusso-Choueril P. K.; Brasil Choueri R.B.; Lombardi A.T., Machado E.C., 2011. The 401 dynamics of fluorescent dissolved organic matter in the Paranaguá estuarine system, 402 Southern Brazil, Brazilian Journal of Oceanography 59 (4).

403 http://dx.doi.org/10.1590/S1679-87592011000400002

404 Hilal N., Oluwaseun O. Ogunbiyi, Nick J. Miles, Rinat Nigmatullin. 2005. Methods 405 Employed for Control of Fouling in MF and UF Membranes: A Comprehensive 406 Review. Separation Science and Technology, 40 (10), 1957-2005; doi: 10.1081/SS$407 \quad 200068409$

408 Howe K.J., Clark M.M., 2006. Effect of coagulation pretreatment on membrane 409 filtration performance, Journal American Water Works Association, 98( 4), 133-146

410 Howe, K.J.; Clark, M.M., 2002. Fouling of microfiltration and ultrafiltration membranes 411 by natural waters. Environmental Science and Technology, 36 (16), 3571-3576.

412 Huang Haiou., Schwab K., Jacangelo J. G., 2009. Pretreatment for Low Pressure 413 Membranes in Water Treatment: A Review. Environmental Science and Technology, 41443 (9), 3011-3019;

415 doi: 10.1021/es802473r http://pubs.acs.org/doi/abs/10.1021/es802473r

416 Hua G., Reckhow D.A., Abusallout I., 2015. Correlation between SUVA and DBP 417 formation during chlorination and chloramination of NOM fractions from different 418 sources. Chemosphere 13082 - 89; doi: 10.1016/j.chemosphere.2015.03.039 
419 Jermann, D.; Pronk, W.; Meylan, S.; Boller, M., 2007. Interplay of different NOM 420 fouling mechanisms during ultrafiltration for drinking water production. Water 421 Research 41 (8), 1713-1722; doi:10.1016/j.watres.2006.12.030

422 Judd S.J., Hills P., 2001, Optimisation of combined coagulation and microfiltration for 423 water treatment. Water Research, 35 (12), 2895 - 2904; doi:10.1016/S0043$424 \quad 1354(00) 00586-8$

425 Lee Jeong-Dae, Lee Sang-Ho, Jo Min-Ho, Park Pyung-Kyu, Lee Chung-Hak, Kwak 426 Jong-Woon. 2000. Effect of Coagulation Conditions on Membrane Filtration 427 Characteristics in Coagulation - Microfiltration Process for Water Treatment, 428 Environmental Science technology 34 (17), 3780-3788; DOI: 10.1021/es9907461

429 Li Y., Zhanga W., Xiaojian Z., Chao C., Jun W., 2010. Characterization of fouling in 430 immersed polyvinylidene floride hollow fire membrane ultrafitration by particles and 431 natural organic matter. Desalination and Water Treatment 18, 309-31; 432 doi:10.5004/dwt.2010.1814

433 Lin, C. F.; Lin, T. Y.; Hao, O. J., 2000. Effects of humic substance characteristics on 434 UF performance. Water Research 34 (4), 1097-1106; doi:10.1016/S0043435 1354(99)00273-0

436 Kabsch-Korbutowicz M., Biłyk A., Mołczan M., 2006. The Effect of Feed Water 437 Pretreatment on Ultrafiltration Membrane Performance, Polish Journal of 438 Environmental Studies, 15 (5), 719-725

439 Kim J., Shi W., Yuan Y., Benjamin M.M., 2007. A serial filtration investigation of 440 membrane fouling by natural organic matter, Journal of Membrane Science 294 (1-2), 441 115-126; doi:10.1016/j.memsci.2007.02.020, 
442 Kim J., Cai Z., Benjamin M.M., 2008. Effects of adsorbents on membrane fouling by 443 natural organic matter, Journal of Membrane Science 310, 356-364. 444 doi:10.1016/j.memsci.2007.11.007

445 Kim J., Cai Z., Benjamin M.M., 2010. NOM fouling mechanisms in a hybrid 446 adsorption/membrane system. Journal of Membrane Science 349, 35-43. 447 doi:10.1016/j.memsci.2009.11.017

448 Malczewska B., Liu J., Benjamin M.M., 2015. Virtual elimination of MF and UF fouling 449 by adsorptive pre-coat filtration, Journal of Membrane Science 04 479:159-164. doi: 450 10.1016/j.memsci.2015.01.032

451 Mostofa K. M., Honda Y., Sakugawa H., 2005. Dynamics and optical nature of 452 fluorescent dissolved organic matter in river waters in Hiroshima prefecture, 453 Japan. Geochem. J. 39, 257-271.

454 Nguyen, T.; Fan, L.; Roddick, F.A.; Harris, J.L., 2009. A comparative study of 455 microfiltration and ultrafiltration of activated sludge-lagoon effluent, Desalination 236 $456 \quad$ (2009) 208-215.

457 Pikkerainen A.T., Judd S.J., Jokela J., Gillberg L., 2004, Pre-coagulation for 458 microfiltration of an upland surface water. Water Research 38 (2), 455-65.

459 Silvia H.S. Fatibello A., Augusto A. Vieira H., Fatibello-Filho O., 2004. A rapid 460 spectrophotometric method for the determination of transparent exopolymer particles 461 (TEP) in freshwater; Talanta 9. 62 (1), 81-5. doi: 10.1016/S0039-9140(03)00417-X.

462 Tsuneda, S., Aikawa, H., Hayashi H., Yuasa A., Hirata A., 2003. Extracellular 463 polymeric substances responsible for bacterial adhesion onto solid surface. FEMS 464 Microbiol. Lett., 223, 287-292. 
465 Yu H., Liang H., Qu F., Han Zheng-shuang, Shao S., Chang H., Li G., 2015. Impact 466 of dataset diversity on accuracy and sensitivity of parallel factor analysis model of 467 dissolved organic matter fluorescence excitation-emission matrix, Sci Rep. 5 (10207). 468 doi: $10.1038 /$ srep10207

469 Yuan W., Zydney, A. L., 1999. Humic acid fouling during microfiltration. Journal of 470 Membrane Science 1999, 157 (1), 1-12.

471 Yuan, W.; Zydney, A. L., 2000. Humic acid fouling during ultrafiltration. Environmental 472 Science \& Technology, 34, (23), 5043-5050.

473 Zhang W., Zhang W., Zhang X., Amendola P., Hu Q., Chen Y. 2014. Characterization 474 of dissolved organic matters responsible for ultrafiltration membrane fouling in algal 475 harvesting, Algal Research, 2(3), 223-229.

476

477

478

479

480

481

482 


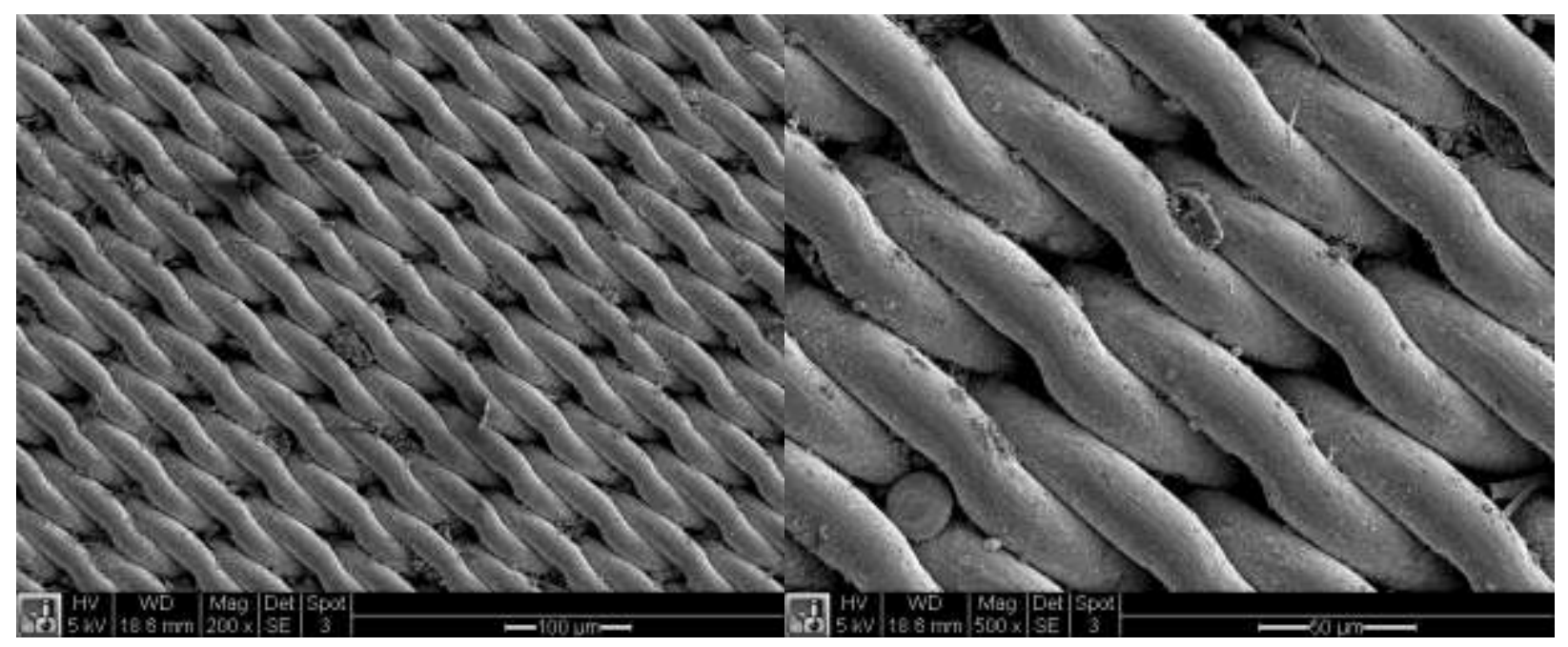

484

485 Figure 1. SEM images for stainless steel mesh.

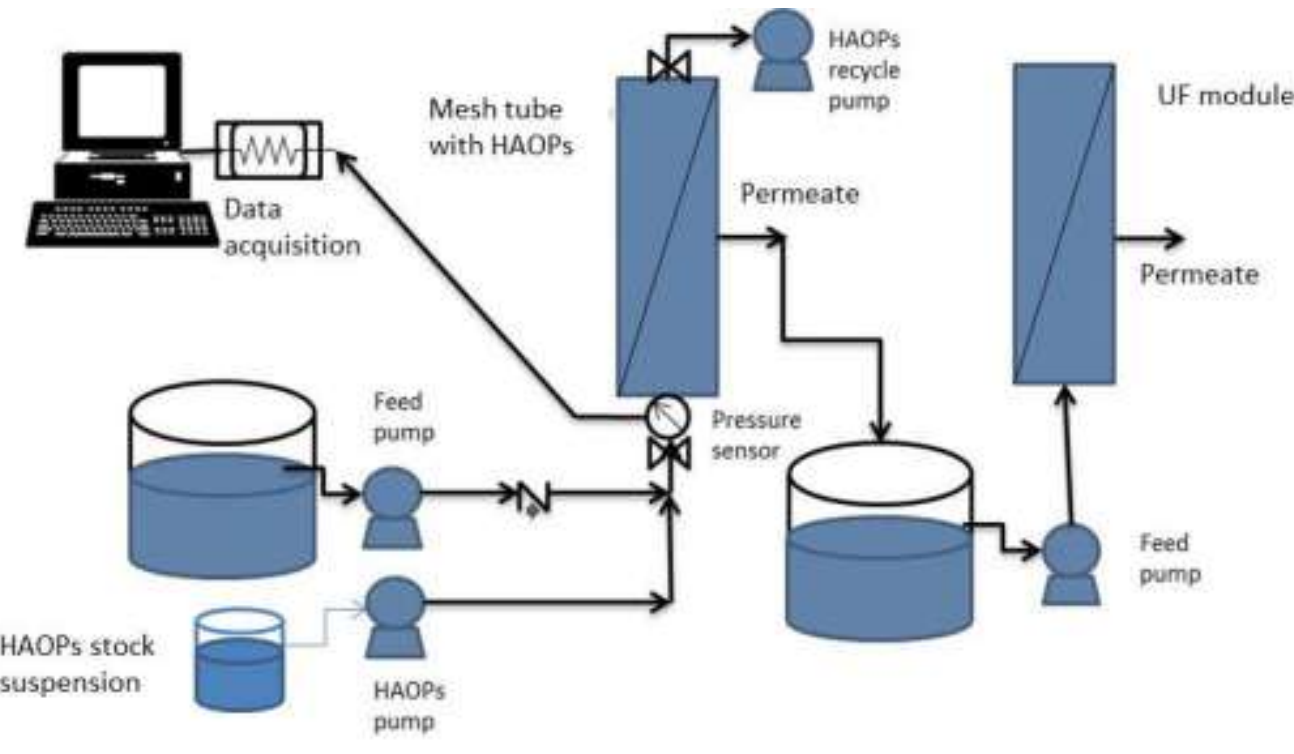

488 Figure 2. Schematic diagram of the test setup. 


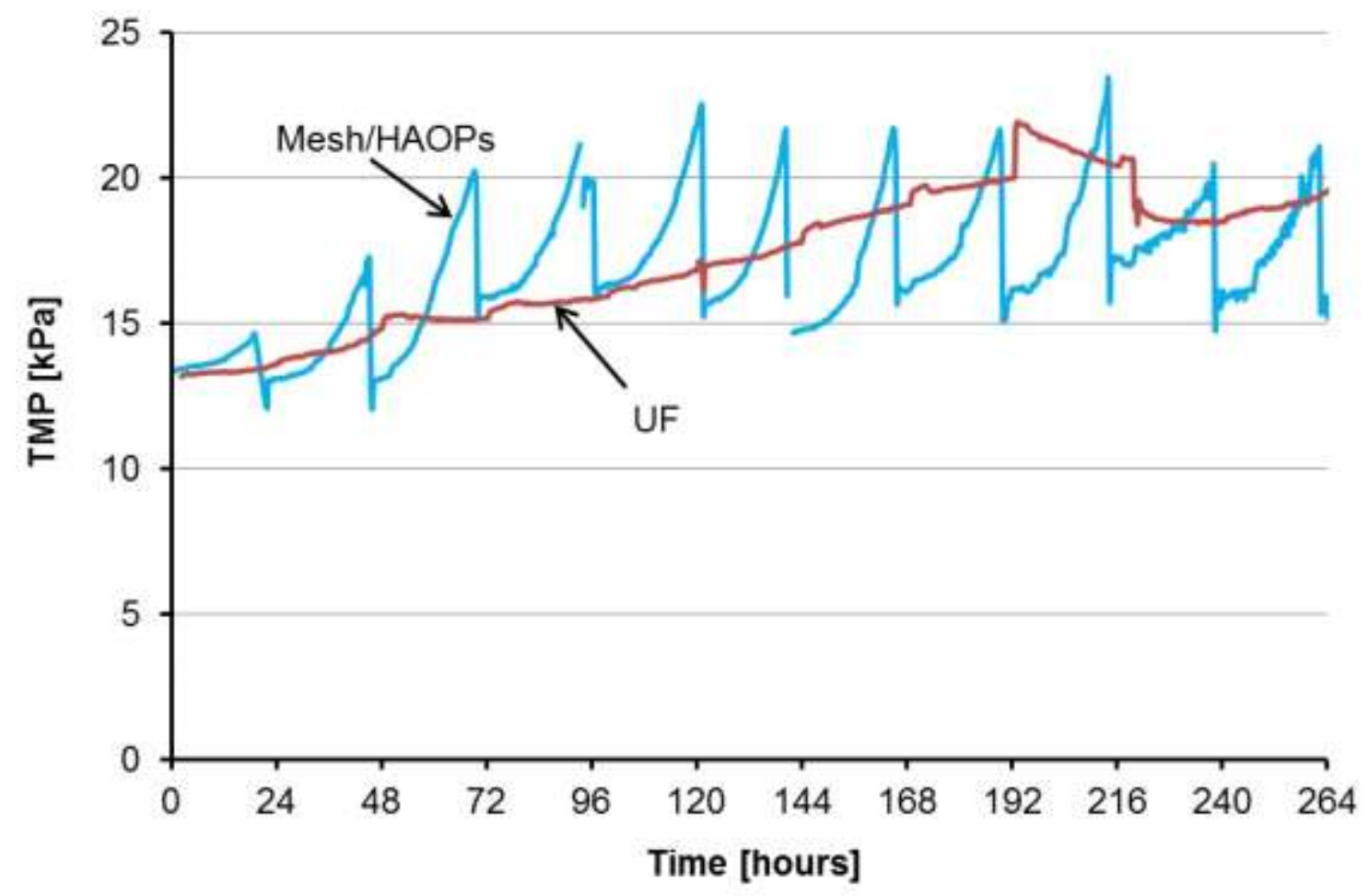

490

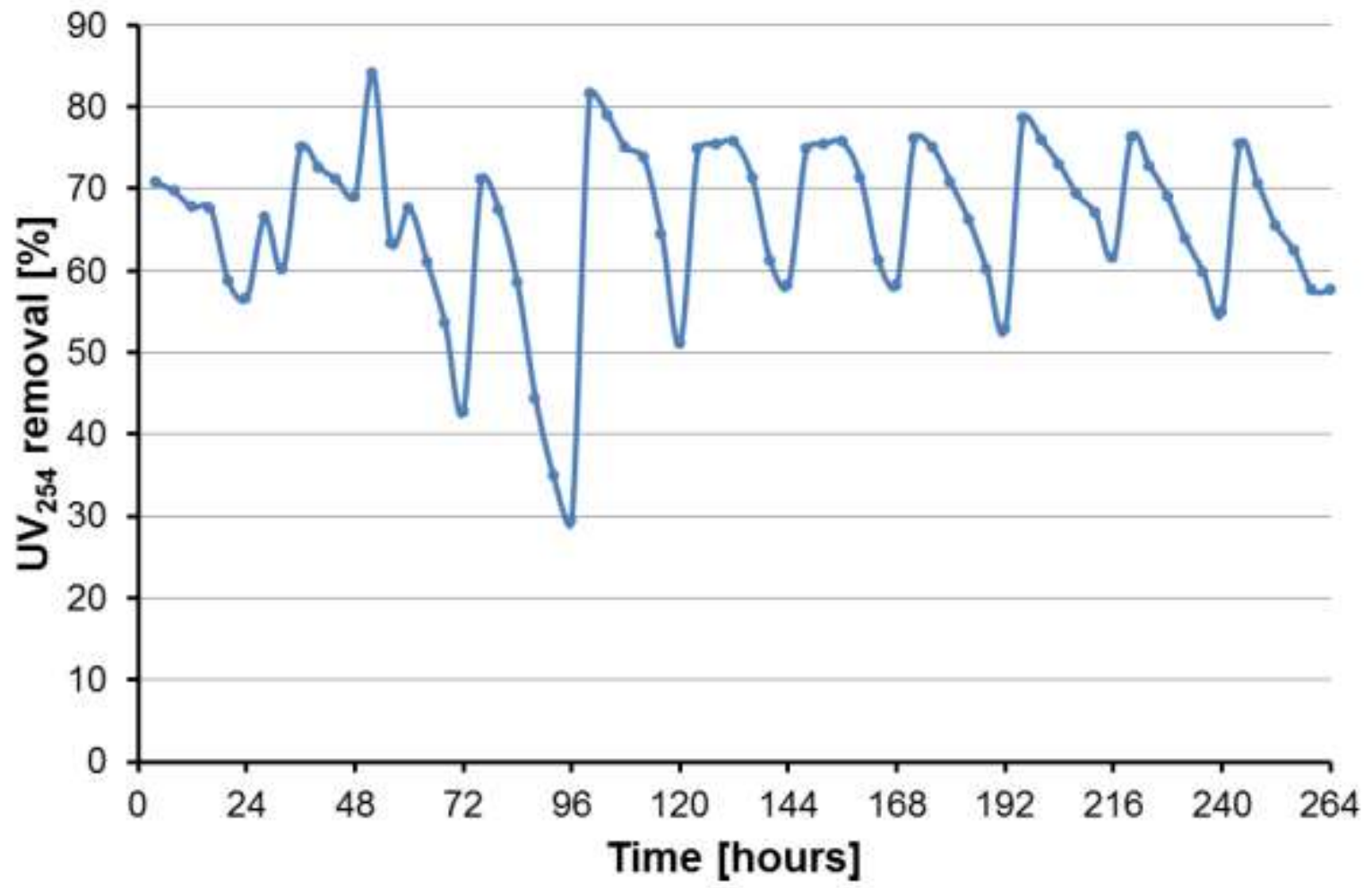

491

492 Figure 3. (a) Pressure loss across the system components during 11 days of filtration 493 and (b) $\mathrm{UV}_{254}$ removal by the system. Fluxes were $150 \mathrm{LMH}$ to the HAOPs unit and 
$87 \mathrm{LMH}$ to the UF membrane. HAOPs unit was backwashed daily, but UF unit was

495 not backwashed at all.

496

497

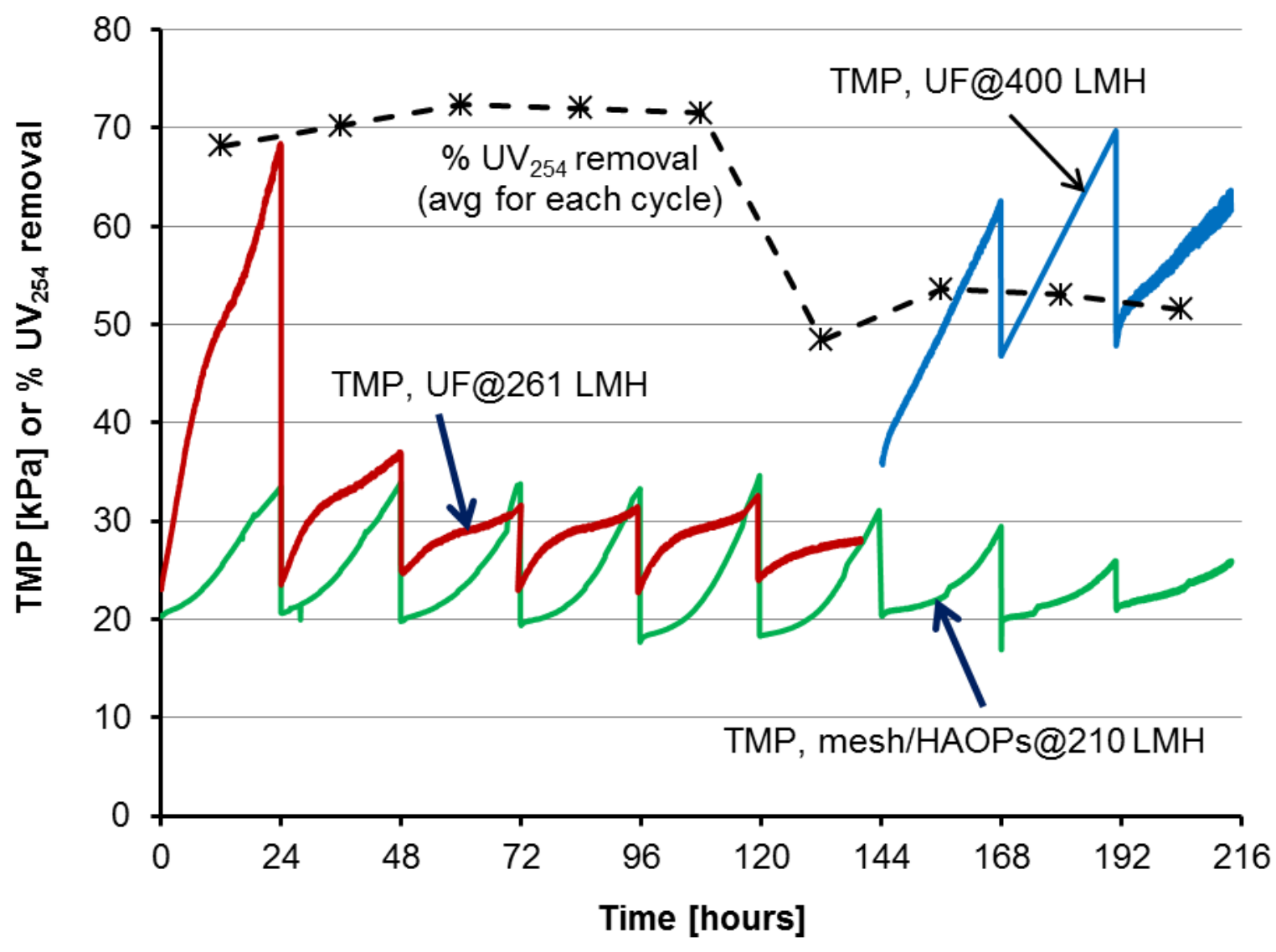

499 Figure 4. $\mathrm{UV}_{254}$ removal and TMP across the system components for operation at 500 high fluxes. 


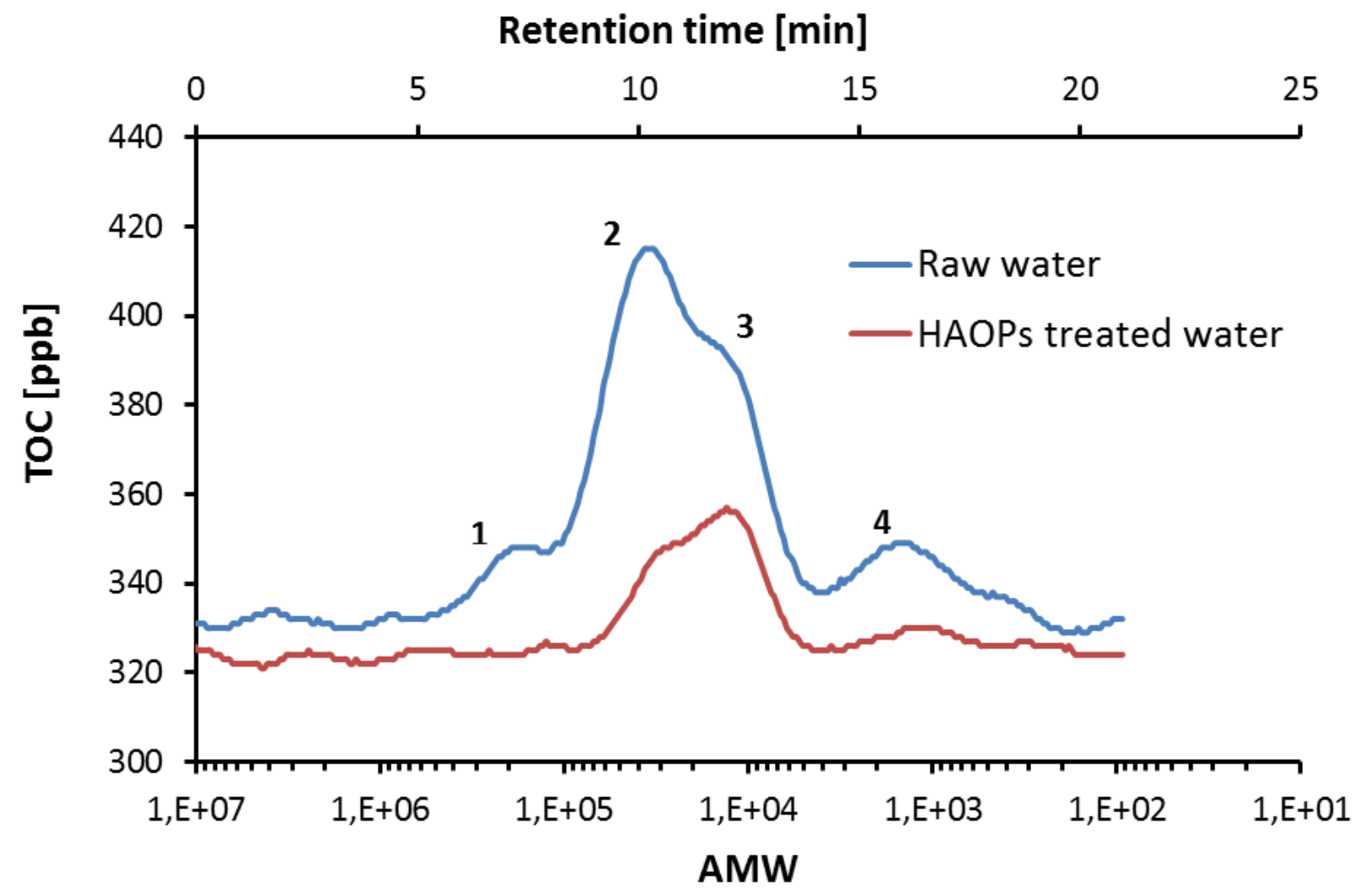

502

503 Figure 5. SEC elution profile of LU water and HAOPs-treated water.

504

505 

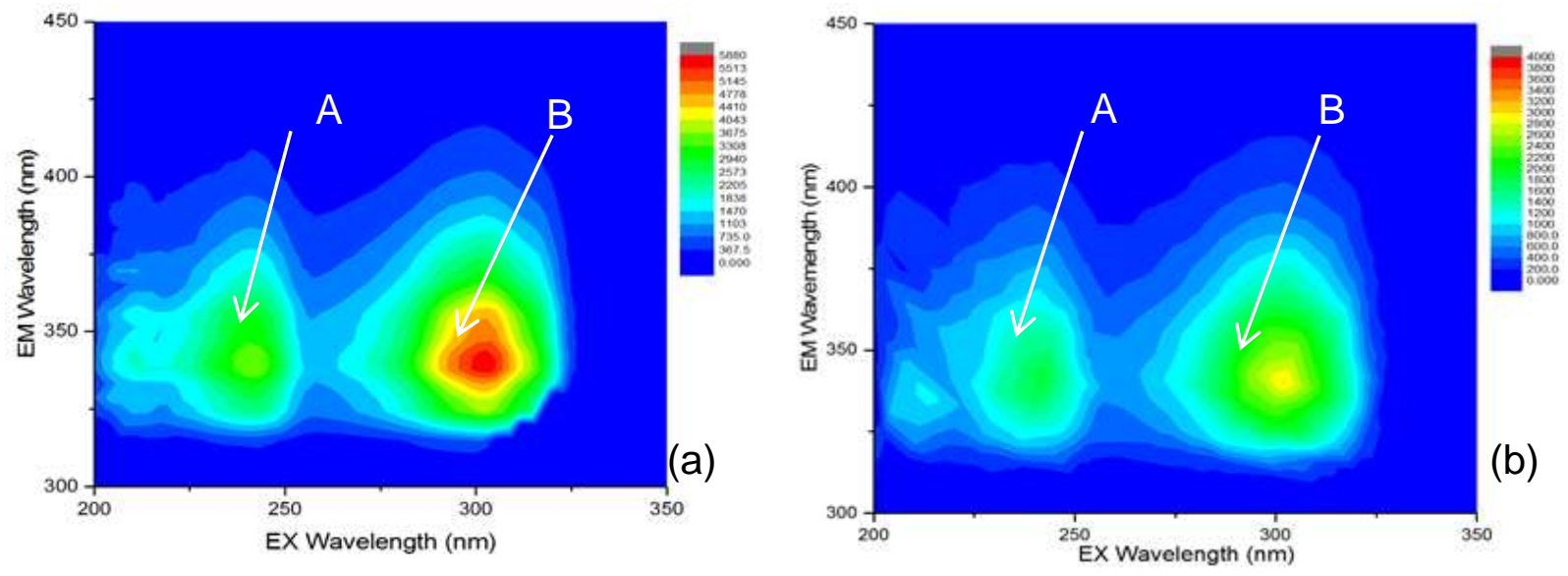

507

508 Figure 6. EEM fluorescence spectra of (a) raw and (b) HAOPs-treated water. 
510

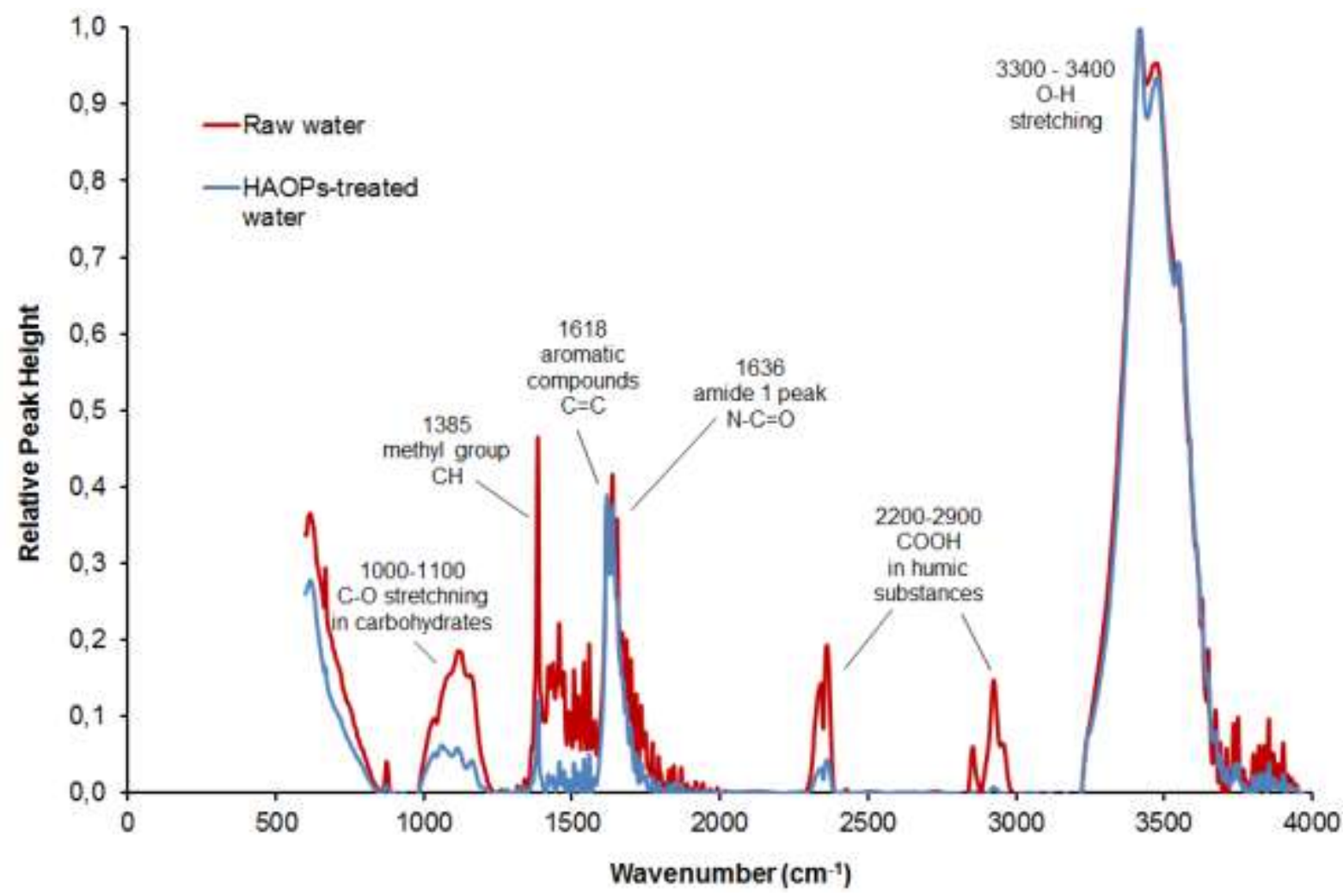

512 Figure 7. Normalized FTIR spectra of raw and HAOPs-treated LU water. 
514 Table 1. DBP formation in simulated distribution system (SDS) tests with raw and HAOPs-treated water. (a)

\begin{tabular}{|c|c|c|c|c|c|c|c|c|c|c|c|c|c|c|c|c|}
\hline & $\begin{array}{l}\text { Chlorine } \\
\text { residual }\end{array}$ & TCM & DCBM & DBCM & TBM & THM4 & MCAA & MBAA & DCAA & BCAA & TCAA & DBAA & BDCAA & CDBAA & TBAA & HAA9 \\
\hline & \multicolumn{16}{|c|}{ WINTER 2014 (24-h composite) } \\
\hline Raw water & 1.2 & 77.3 & 17.4 & 0.9 & 6.0 & 124.4 & bdl. & 0.2 & 24.2 & 2.8 & 39.0 & 0.2 & 3.8 & 0.2 & 0.0 & 70.5 \\
\hline \multirow[t]{2}{*}{ HAOPs-Treated } & 0.8 & 17.7 & 7.8 & 2.5 & 5.2 & 33.2 & bdl. & 0.1 & 3.2 & 1.9 & 1.4 & 0.2 & 1.1 & 0.3 & 0.0 & 8.3 \\
\hline & \multicolumn{16}{|c|}{ SPRING 2015 (24-h composite) } \\
\hline Raw water & 1.1 & 65.8 & 14.1 & 6.3 & 0.7 & 86.9 & bdl. & 2.6 & 21.1 & 5.5 & 31.0 & 0.8 & 4.1 & 6.3 & 2.2 & 73.6 \\
\hline \multirow[t]{2}{*}{ HAOPs-Treated } & 1.1 & 16.4 & 10.2 & 6.3 & 0.7 & 33.6 & bdl. & 1.1 & 5.1 & 4.0 & 7.2 & 0.7 & 2.5 & 4.0 & 1,7 & 26.3 \\
\hline & \multicolumn{16}{|c|}{ SPRING, 2015 (two discrete HAOPs-treated samples analyzed) } \\
\hline Raw water & 1.1 & 78.1 & 15.3 & 5.6 & 0.4 & 99.4 & bdl. & 0.4 & 17.9 & 4.3 & 16.1 & 0.6 & 2.7 & 5.3 & 3.7 & 68.0 \\
\hline $\begin{array}{c}\text { HAOPs-Treated } \\
0.5 \mathrm{hr}\end{array}$ & 1.1 & 14.6 & 4.3 & 4.2 & 0.6 & 23.7 & bdl. & 0.1 & 7.2 & 2.8 & 8.3 & 0.8 & 1.1 & 5.8 & 3.8 & 31.7 \\
\hline $\begin{array}{l}\text { HAOPs-Treated } \\
20 \mathrm{hr}\end{array}$ & 1.4 & 39.0 & 4.5 & 2.8 & 0.6 & 46.8 & bdl. & 0.5 & 10.2 & 1.8 & 16.9 & 0.4 & 1.9 & 4.6 & 0.3 & 39.8 \\
\hline
\end{tabular}

517 (a) Chlorine residual in $\mathrm{mg} / \mathrm{L}$ as $\mathrm{Cl}_{2}$; all other values in $\mu \mathrm{g} / \mathrm{L}$. 
EFFICACY OF HYBRID ADSORPTION/MEMBRANE PRE-TREATMENT FOR LOW PRESSURE MEMBRANE

Malczewska B., Benjamin M.M.

Civil and Environmental Engineering, University of Washington

Box 352700, Seattle, WA 98195-2700

email: markbenj@uw.edu Phone: 206-543-7645
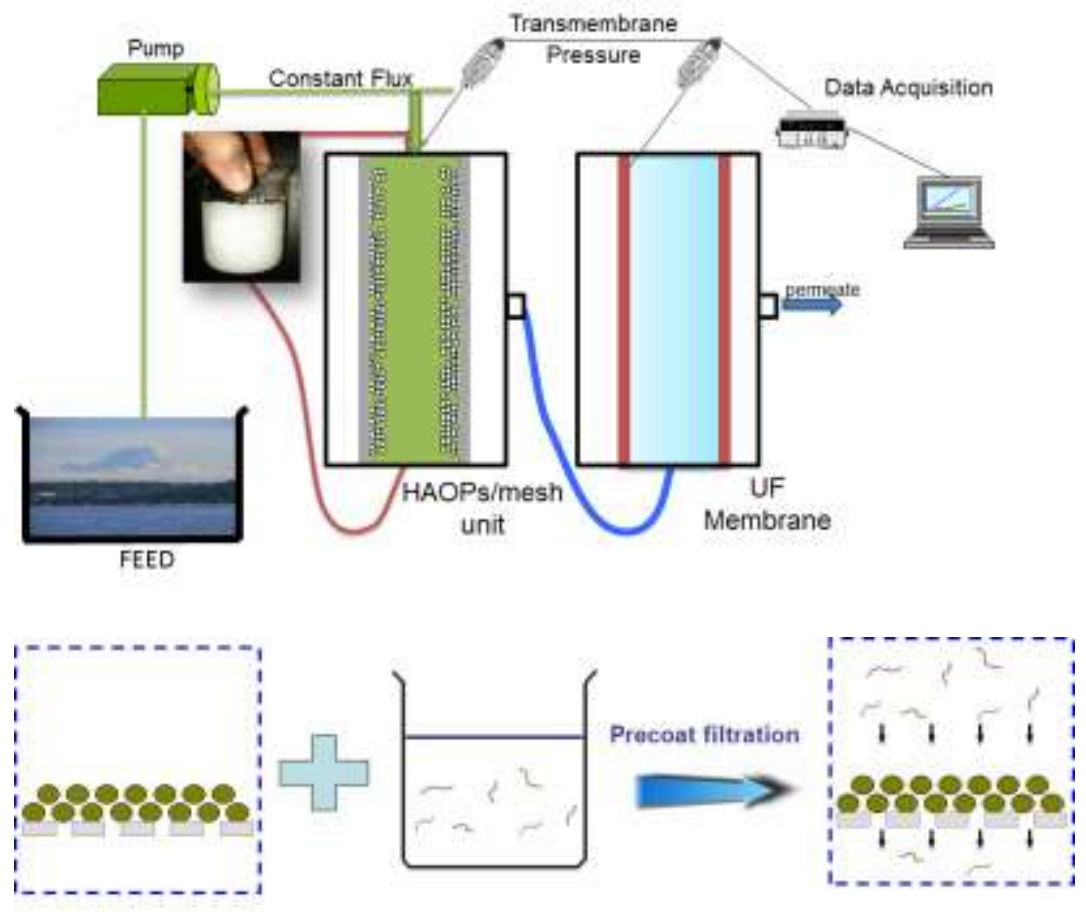